\title{
Alveolar hydatid disease of the liver with Budd-Chiari syndrome
}

\author{
M. S. KHUROO \\ M.D., D.M. \\ D. V. DAtTa \\ M.D., Ph.D. \\ A. KHOSHY \\ M.D., D.M. \\ S. K. Mitra \\ M.S.

\begin{abstract}
P. N. ChHuttani
M.D., F.A.M.S.

Department of Gastroenterology, Postgraduate Institute of Medical Education and Research,
\end{abstract} \\ Chandigarh-160012 (India)
}

\begin{abstract}
Summary
Alveolar hydatid disease in man is the intermediate stage in the life cycle of the tapeworm Echinococcus multilocularis. This is a rare disease resticted to very few areas of the world. The occurrence of this disease in India is now described for (so far as the authors are aware) the first time. Some unusual features of the disease are highlighted in this patient. The hepatic lesion had infiltrated into the right atrial wall resembling an atrial tumour. The ostium of the inferior vena cava was occluded, causing Budd-Chiari syndrome. The radiological and haemodynamic study of the hepatic outflow tract in this disease are documented.
\end{abstract}

\section{Introduction}

Alveolar hydatid disease of the liver is a rare entity restricted to very few areas of the world. So far as the authors are aware, no case of this disease has yet been reported from the Indian subcontinent. The clinical, biochemical, hepatic haemodynamic, radiological and post-mortem findings from a patient with this disease are now described.

\section{Case report}

A 29-year-old man from Uri Kashmir was admitted to Nehru Hospital, Postgraduate Institute of Medical Education and Research, Chandigarh, in July 1977 , with upper abdominal pain and exertional dyspnoea of 18 months' duration. Six months before admission he had had swelling of the feet and legs. $\mathrm{He}$ had lost $10 \mathrm{~kg}$ of weight during his illness. Physical examination revealed pulse rate of $50 / \mathrm{min}$ with a BP of $120 / 70 \mathrm{mmHg}$. There was no jaundice or lymphadenopathy. Jugular venous pressure was raised $4 \mathrm{~cm}$ above the manubrium sterni. Prominent veins, with flow from below upwards, were present over the lumbar region. Feet and legs revealed pitting oedema and pigmentation. Varicosity of the long and the short saphenous venous tributaries was present in both legs. The liver was enlarged $4 \mathrm{~cm}$ below the right costal margin. It was firm and non tender. Vertical span on percussion was $18 \mathrm{~cm}$. The spleen was firm and palpable $4 \mathrm{~cm}$ below the left costal margin. There was no bruit, rub or free fluid in the abdomen. Cardiac examination revealed an apex beat in the 4th intercostal space, just inside the anterior axillary line. An early diastolic murmur was heard in the 3rd left intercostal space. A middiastolic rumble at the cardiac apex was heard by some examiners.

\section{Laboratory tests}

$\mathrm{Hb}, 10 \cdot 15 \mathrm{~g} / \mathrm{dl}$; ESR $35 \mathrm{~mm} / 1 \mathrm{st} \mathrm{hr}$ (Westergren); urine examination: total and differential leucocyte counts, serum electrolytes, blood urea and serum creatinine were all within normal limits. Serum bilirubin was $12.83 \mu \mathrm{mol} / \mathrm{l}$; serum albumin, $29 \mathrm{~g} / \mathrm{l}$; serum globulin $33 \mathrm{~g} / \mathrm{l}$; aspartate transaminase, 23 i.u./l; alanine transaminase, 10 i.u./l. Chest X-ray showed an elevated right dome of diaphragm with plate-like atelectasis at the right base. The heart seemed normal and an ECG was within normal limits. Radiological and endoscopic examination of the upper gastrointestinal tract was normal. Liver scan showed a large filling defect situated in the superior and anterior part of the liver. Casoni's intradermal test was positive and echinococcal haemagglutination titres were positive in $1: 360$. VDRL was negative on 2 occasions. Alphafetoproteins from peripheral and hepatic venous blood were negative by counterimmunoelectrophoresis technique. $\mathrm{HB}_{\mathrm{s}} \mathrm{Ag}$ was negative and bromsulphthalein retention at $45 \mathrm{~min}$ was $17 \cdot 5 \%$. 
A double venous catheter study from right antecubital and right femoral route was attempted. The upper catheter reached the right atrium but failed to enter the inferior vena cava on repeated attempts. The lower catheter went freely into the intrahepatic portion of the inferior vena cava and on advancing would enter the right hepatic vein. Repeated attempts to advance the catheter into the right atrium failed. Inferior vena caval pressure was $25 \mathrm{mmHg}$; free hepatic vein pressure was also $25 \mathrm{mmHg}$. Hepatic blood flow was estimated according to the method of Caesar et al. (1961) using a constant infusion of indocyanine green. The estimated hepatic blood flow was $800 \mathrm{ml} / \mathrm{min}$ (normal $1351 \pm 148 \mathrm{ml} / \mathrm{min}$ ). The inferior venacavogram is shown in Fig. 1. A right free hepatic venogram revealed some abnormal vessels and pooling of the contrast, suggesting the presence of a cavity (Fig. 2). A needle biopsy of the liver was done and repeated after 12 weeks: the central veins, the hepatic lobules and the portal tracts were unremarkable. On both occasions the tissue was adequate for interpretation.

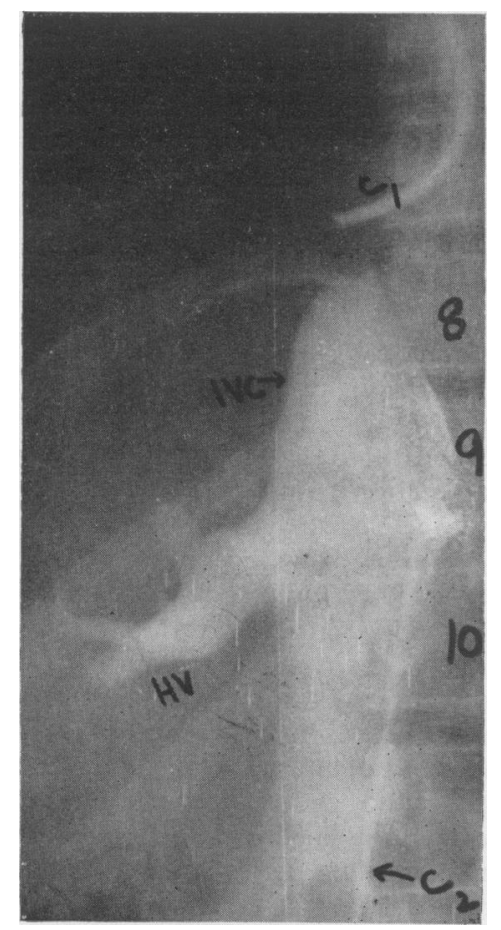

Fig. 1. Inferior venacavogram. $40 \mathrm{cc}$ of Conray 420 were injected through a catheter $\left(C_{2}\right)$ placed in inferior vena cava (IVC). Complete block of the vein was seen at the level of the 8th dorsal vertebra. Right hepatic vein (HV) was patent. Left hepatic vein was not filled by the contrast. The catheter $\left(C_{1}\right)$ in the right atrium failed to enter the IVC on repeated attempts. The numbers $(8,9$, 10) correspond to the particular dorsal vertebrae.

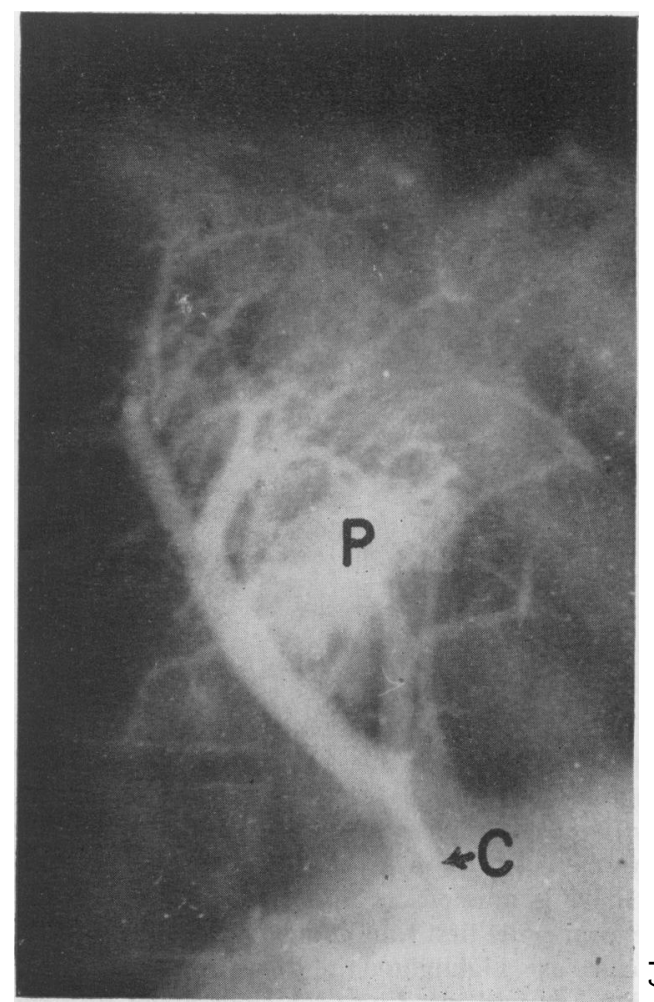

Fig. 2. Right hepatic venogram. $15 \mathrm{cc}$ of Conray 420 were injected through a catheter (C) placed in the right hepatic vein. Considerable pooling of the contrast (P) suggested presence of a cavity. The finer venous radicles showed block and tortuosity.

The radiological findings were interpreted as $\overrightarrow{\overrightarrow{0}}$ showing membranous obstruction of the inferior vena cava. Stenotic lesions of the inferior vena cava above the ostium of hepatic veins can be caused by

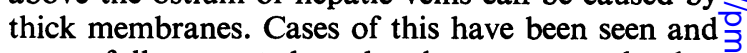
successfully operated on by the present and other workers (Takeuchi et al., 1971; Datta et al., 1972). The patency of the right hepatic vein and occlusion of the left hepatic vein on the cavogram was consistent with this diagnosis. Hydatid of the liver was 0 considered in view of the filling defect in the liver scan with a positive Casoni's test and hydatid serology. Its aetiological role in the inferior vena cava block was thought unlikely. Dilatation of the $N$ stenosed inferior vena caval segment was considered. $N$ On opening up the right atrium, a firm nodular lesion $N$ was felt in its lateral wall. The inferior vena caval ${ }_{\sigma}^{\omega}$ opening could not be identified. The liver felt hard on palpation and the incision was extended and the abdomen opened up. A hard mass was felt in the superior surface of the liver which was adhering to ${ }_{+}^{+}$ the diaphragm. A biopsy from the hepatic lesion was taken. This revealed laminated hyaline structures $\overrightarrow{\mathbb{D}}$ 
characteristic of hydatid disease of the liver. The patient developed postoperative shock and died on the 6th postoperative day.

At post-mortem the liver weighed $2.84 \mathrm{~kg}$ and a hard mass with central cavitation was present on the superior surface (Fig. 3). The mass had involved the

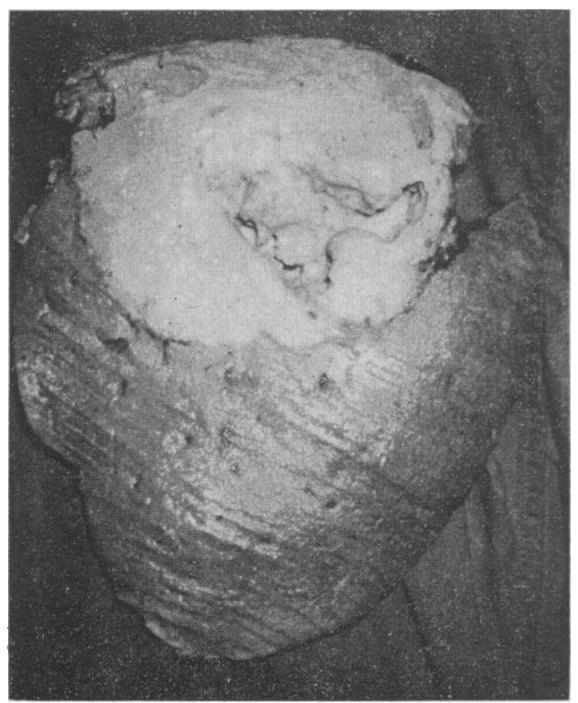

FIG. 3. Photograph of the vertical cut section of the liver at post-mortem. A $14 \times 18 \mathrm{~cm}$ mass is seen in the upper part of the liver. The central area shows deep cavitation. diaphragm over it and extended to infiltrate the wall of the right atrium and left pleural cavity. The right atrium from inside felt firm and nodular. The ostium of the inferior vena cava was occluded by the disease process involving the atrium. The left hepatic vein was patent but compressed by the mass.

Microscopically, numerous cysts of Echinococcus multilocularis were seen embedded in thick fibrous tissue (Fig. 4). They had grown into the diaphragm, right atrium and left pleural cavity, producing the same fibrous tissue response in these areas. The rest of the liver showed patchy areas of centrilobular haemorrhages and necrosis with reversed lobulation (Fig. 5). The spleen showed features of congestive splenomegaly. Rheumatic heart disease involving aortic, mitral and tricuspid valves was present. Kidneys were unremarkable.

\section{Discussion}

E. multilocularis infection is restricted to a few areas of the world, namely Bavaria, Switzerland, France, U.S.S.R. including Siberia (Semenove and Rezektsii Pecheni, 1954; Rizk, Tayyarah and Ghandur-Manymneh, 1971; Schamaun, 1972; Hess, Eckert and Frohlich 1974; Rudofsky, Wolfert and Ran, 1975; Gilsanz et al., 1977), Alaska and northern Japan (Spencer, 1973; Thompson, Chisholm and Tank, 1972). There are no published reports of this disease occurring in India. The patient had never been out of India. This

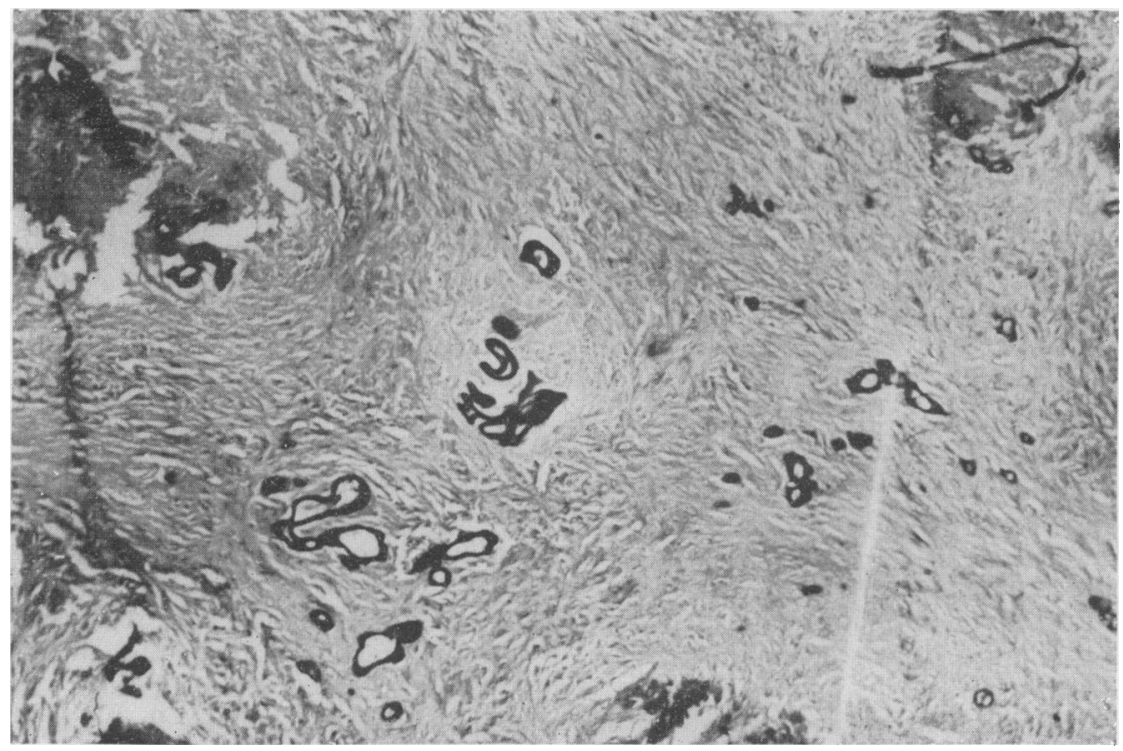

FIG. 4. Post-mortem photomicrograph of the liver. Numerous cysts of varying sizes and shapes are seen embedded in the thick collagen tissue. The cyst wall was staining intensely positive with PAS. No scolices were present (PAS, $\times 100$ ). 


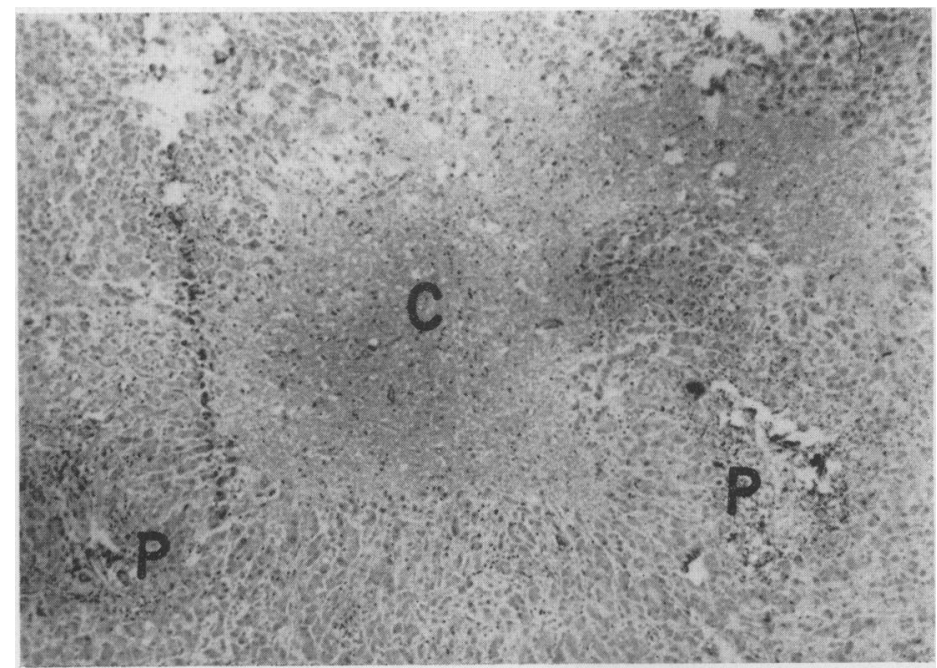

Fig. 5. Post-mortem photomicrograph of liver. The centrilobular area (C) showed massive haemorrhage and necrosis. The central veins were not recognized. Two portal tracts (P) are seen. The periportal hepatocytes were spared, with mild sinusoidal dilatation $(\mathrm{HE}, \times 100)$.

suggests that the disease exists in some parts of India, and this needs investigating. The Kashmir valley is situated in northern India and is surrounded by the Himalayas. The patient was born in the thickly forested area in the western part of the valley. Wild animals and rodents are common in this region. The life-cycle of this tapeworm is completed in the definitive host, fox, wolf, dog, via the intermediate host, a rodent. Man becomes infected through eating wild fruit contaminated with the eggs of the worm (which are excreted with the faeces) or by handling infected animals (Spencer, 1973).

There is one fundamental difference between the hydatid due to $E$. granulosus and that due to $E$. multilocularis: the former has a definite outer, limiting membrane and the whole structure is confined to a fluid-filled cavity with minimal tissue response from the host; the other lacks exocyst, and the larval structures grow into the host tissue causing tissue destruction, inflammation and fibrosis (Samuels and Fosmoe, 1970; Thompson, Chisholm and Tank, 1972; Spencer, 1973); this gives rise to a tumour which cavitates in the centre. The larval structures do not contain scolices and grow into surrounding structures resembling invasive carcinoma. All these features were seen in the present patient.

It was shown that alveolar hydatid disease of the liver caused the Budd-Chiari syndrome in this patient. The radiological findings resembled membranous obstruction of the intrahepatic portion of the inferior vena cava. Such a presentation of the disease appears to be unique. There has been one case of alveolar hydatidosis of the liver whictao involved the inferior vena cava but it was an is io dental laparotomy finding hindering total resection and angiographic studies were not done. There hầ been 3 instances reported of the Budd-Chiar syndrome being caused by E. granulosus hydatio (Parker, 1959; Raciti, 1972) but, again, those्ष patients were not examined haemodynamically of radiologically.

The disparity between the liver histology on needle biopsy and at post-mortem was related to the sampling error of the former. A similar problem in $a^{-}$ patient with membranous obstruction of the inferiog vena cava has been the focus of an earlier publication: (Datta et al., 1973). The authors feel that haemo3 dynamic and radiological investigations are morè useful than liver biopsies in the diagnosis of Budd 3 Chiari syndrome caused by inferior vena cava $\vec{b}$
disease.

The alveolar hydatids in this patient had infiltrate into the right atrium producing a resemblance to tumour. The involvement of the lesser omentunf with obstructive jaundice and extrahepatic portah hypertension has been described (Schamaun, 1972) N The involvement of the diaphragm, spleen and other adjoining structures has also been reported (Semenove and Rezektsii Pencheni, 1954; Samuel and Fosmoe, 1970). Occasionally, liver cysts ge detached and behave as tumour emboli (Spencer, 1973). Recently, 3 cases have been described of cardiac hydatidosis due to $E$. granulosus producingD 
pulmonary hypertension as result of embolization into pulmonary arteries (Gilsanz et al., 1977).

Radiological changes in hydatid disease have been the focus of considerable interest (Thompson et al., 1972). Different types of calcification in the 2 types of hydatidosis have been described. The present case did not show calcification either radiologically or histopathologically. The presence of an abnormal vascular pattern and the pooling of the contrast on free hepatic venogram in the patient was due to the mass lesion with central cavitation. There have been no such comparable studies in patients with alveolar hydatidosis. Coeliac angiography in such patients has shown obliteration, dislocation, and corkscrew collaterals of the hepatic vessels (Rudofsky et al., 1975). The angiographic and venographic features of the hydatid disease caused by $E$. granulosus have been well described (Rizk et al., 1971).

Serological tests in alveolar hydatidosis have given positive reaction in a higher percentage of patients and in much higher titres (Hess et al., 1974). This is to be expected as there is a greater crossover of the antigen from the cysts in these patients owing to the absence of a cyst wall.

The therapeutic problems of this disease are considerable, and massive hepatic resections are required (West, Hilman and Rausch, 1963); even then, the radical removal of the disease process is rare and results have been unsatisfactory. Radical removal of the lesion in the present case was impossible owing to the extensive involvement of the extra-hepatic tissues. Recent observations of the effective antilarval action of mebendazole against many species of cestode (Heath, Christie and Chevis, 1975) need to be explored in this disease.

\section{References}

Caesar, J., Shaldon, S., Chiandussi, L., Guevara, L. \& SHERLOCK, S. (1961) The use of indocyanine green in the measurement of hepatic blood flow and a a test of hepatic function. Clinical Science, 21, 43.

DatTa, D.V., Saha, S., Samanta, A., Chugh, K.S. \& Chhuttani, P.N. (1972) Chronic Budd-Chiari syndrome due to obstruction of the inferior vena cava. Gut, 13, 372 .
Datta, D.V., Saha, S., Patowary, J.C. Samanta, A.K.S., Gupta, B.B., Bhagwal, A.G. \& Chhuttani, P.N. (1973) Partially obstructed hepatic portion of inferior vena cava diagnosed by percutaneous hepatography. Angiology, 24, 434.

Gilsanz, V., Campo, C., Gue, R., Estella, J., Estrada, R.V., Perez-Oteiza, C., Rebollar, J.T. \& Zarco, P. (1977) Recurrent pulmonary embolism due to hydatid disease of heart; study of 3 cases, one with intermittent tricuspid valve obstruction (atrial pseudomyxoma). British Heart Journal, 39, 553.

Heath, D.D., Christie, M.J., Chevis, R.A. (1975) The lethal effect of mebendazole on secondary Echinococcus granulosus, cysticerci of Taenia pisiformis and tetrathyridia of Mesocestoides corti. Parasitology, 70, 273.

Hess, U., ECKERT, J., Frohlich, A. (1974) Vergleich serologischer Methoden für die Diagnose der Zystischen und alveolaren Echinokokkose des Menschen. Schweizerische medizinische Wochenschrift, 104, 853.

PARKER, R.G.F. (1959) Occlusion of the hepatic vein in man. Medicine. Baltimore, 38, 369.

RACITI, A. (1972) La sindrome di Budd-Chiari secondaria a cisti d'Echinococco de fegato. Gazzetta internazionale di medicina e chirurgia, 77, 1297.

Rizk, G.K., Tayyarah, K.A., Ghandur-Manymneh, L. (1971) Angiographic changes in hydatid cysts of the liver and spleen. Radiology, 99, 303.

Rudofsky, G., Wolfert, W. \& Ran, R.M. (1975) Angiographische Darstellung der Leberarterien bein Echinococcus alveolaris. Medizinische Klinik, 70, 1641.

Samuels, S. \& Fosmoe, R. (1970) Alveolar hydatid disease with involvement of the inferior vena cava. American Surgery, 36, 698.

Schamaun, M. (1972) Ist die alveolare Echinokokkose der Leber radikal operabel? Schweizerische medizinische Wochenschrift, 102, 224.

Semenove, V.S., Rezektsi Pencheni, O. (1954) Po povodu al veroliarnogo ekunokokka. Vestnik Khirurgii imeni I. I. Grekova, 74, 20.

SPENCER, H. (1973) Tropical Pathology, p. 445. SpringerVerlag, Berlin.

Takeuchi, J., Takada, A., Hasumura, Y., Matsuda, Y. \& IKEDAMI, F. (1971) Budd-Chiari syndrome associated with obstruction of the inferior vena cava. Amerioan Journal of Medicine, 51, 11.

Thompson, W.M., Chisholm, D.P., Tank, R. (1972) Plain film roentgenographic findings in Alveolar hydatid disease -Echinococcus multilocularis. American Journal of Roentgenology, Radium Therapy and Nuclear Medicine, 116, 345.

West, J.T., Hilman, F.J. \& RausCh, R.I. (1963) Alveolar hydatid disease of the liver. Rationale and Technics of surgical treatment. Annals of Surgery, 157, 548. 